\title{
Article
}

\section{Toward the Next Generation of Passive Micromixers: A Novel 3-D Design Approach}

\author{
Mahmut Burak Okuducu ${ }^{1, *(1)}$ and Mustafa M. Aral ${ }^{2}$ (]) \\ 1 School of Civil and Environmental Engineering, Georgia Institute of Technology, Atlanta, GA 30332, USA \\ 2 Design and Simulation Technologies Inc., Istanbul 34860, Turkey; mmaral@live.com \\ * Correspondence: mbokuducu@gatech.edu
}

Citation: Okuducu, M.B.; Aral, M.M.

Toward the Next Generation of

Passive Micromixers: A Novel 3-D

Design Approach. Micromachines

2021, 12, 372. https://doi.org/

$10.3390 / \mathrm{mi1} 2040372$

Academic Editors: Takasi Nisisako and Kwang-Yong Kim

Received: 25 January 2021

Accepted: 28 March 2021

Published: 30 March 2021

Publisher's Note: MDPI stays neutral with regard to jurisdictional claims in published maps and institutional affiliations.

Copyright: (c) 2021 by the authors. Licensee MDPI, Basel, Switzerland. This article is an open access article distributed under the terms and conditions of the Creative Commons Attribution (CC BY) license (https:// creativecommons.org/licenses/by/ $4.0 /)$.

\begin{abstract}
Passive micromixers are miniaturized instruments that are used to mix fluids in microfluidic systems. In microchannels, combination of laminar flows and small diffusion constants of mixing liquids produce a difficult mixing environment. In particular, in very low Reynolds number flows, e.g., $\operatorname{Re}<10$, diffusive mixing cannot be promoted unless a large interfacial area is formed between the fluids to be mixed. Therefore, the mixing distance increases substantially due to a slow diffusion process that governs fluid mixing. In this article, a novel 3-D passive micromixer design is developed to improve fluid mixing over a short distance. Computational Fluid Dynamics (CFD) simulations are used to investigate the performance of the micromixer numerically. The circular-shaped fluid overlapping (CSFO) micromixer design proposed is examined in several fluid flow, diffusivity, and injection conditions. The outcomes show that the CSFO geometry develops a large interfacial area between the fluid bodies. Thus, fluid mixing is accelerated in vertical and/or horizontal directions depending on the injection type applied. For the smallest molecular diffusion constant tested, the CSFO micromixer design provides more than $90 \%$ mixing efficiency in a distance between 260 and $470 \mu \mathrm{m}$. The maximum pressure drop in the micromixer is found to be less than $1.4 \mathrm{kPa}$ in the highest flow conditioned examined.
\end{abstract}

Keywords: micromixer; diffusive mixing; passive mixing; fluid overlapping; sequential injection; segmentation; concentric flow; CFD

\section{Introduction}

Over the past few decades, improvements in microfabrication technology [1] and successful implementation of complex processes at microscales [2] have led the development of microfluidic systems. Micro total analysis systems ( $\mu$ TAS) or lab-on-a-chip (LOC) devices $[3,4]$ are commonly referred to describe a centimeter-size compact unit in which physical, chemical, and biological processes take place in a microchannel network. Micromixers are typically one of the major operational sub-units of microfluidic schemes [5] and are employed to mix fluids using active or passive [6-9] mixing principles. In active mixing, extra modules are required to generate external disturbance forces on the flow domain (e.g., electrical, thermal, magnetic, acoustic, and pressure [10-12]) which develops a complexity in terms of fabrication and integration of these components with other microchip elements $[11,13,14]$. On the contrary, despite offering a relatively poor mixing performance, passive micromixers are simple devices with notable structural and operational advantages. In passive mixing approach, fluid mixing is carried out by exploiting the fluid flow energy within the micromixer and two well-known mixing phenomena: advection and molecular diffusion [4]. As such, additional module and power source requirements are eliminated, and mixing performance is mainly governed by micromixer geometry. Therefore, passive micromixers are typically easy to fabricate, provide simple and stable operating conditions, and offer better integrability $[1,6,15]$, which make these devices prevalent to mix fluids at microscales. 
In passive micromixers, fluid mixing arises as a challenging work due to advectiondominant transport developed in microchannels. Strictly laminar fluid flow that is usually Reynolds (Re) number $<<100[16,17]$ and very low molecular diffusion coefficients (e.g., typically in the range of $10^{-9}-10^{-11} \mathrm{~m}^{2} / \mathrm{s}$ [12]) fundamentally create tough mixing conditions. These difficulties are generally dealt with generating a so-called chaotic fluid motion in special micromixer designs that is typically achieved when $\operatorname{Re}>10-20$. Thus, contact surface area between fluids is enhanced, which in turn expedites diffusive mixing. Typical design and fluid mixing examples may be seen in References [18-21]. At very low Re numbers (e.g., Re $<5-10$ ); however, the effective use of advection is inhibited drastically due to unidirectional fluid flow developed in microchannels. In this case, mixing length increases significantly since mixing process mainly depends on molecular diffusion which is a slow process. Therefore, a long mixing channel is required to obtain an adequate mixing efficiency (e.g., 80\% [22]). Increase in mixing length induces three major problems in microfluidic systems as follows: the integration of the micromixer into a microfluidic scheme, high energy requirement, and a long mixing time.

To date, several passive micromixer geometries have been devised to improve the degree of fluid mixing over a short distance. Although majority of these efforts enhance fluid mixing by developing secondary flows when Re $>10-20$, usually a considerable mixing length increase is observed at very low flow conditions. For instance, Gidde et al. [8] studied a planar passive micromixer with circular and square mixing chambers. The authors performed a wide range of Re number scenarios between 0.1 and 75 and showed that fluid mixing is promoted based on the development of chaotic advection. In both designs, mixing efficiency was improved noticeably when the flowrate increased, and the highest values were achieved at $\operatorname{Re}=75$. The distance that is required to yield $80 \%$ mixing efficiency is reported as approximately $3500,9000,11,000$, and $5000 \mu \mathrm{m}$ for $\operatorname{Re}=0.1,1,5$, and 75, respectively. A similar behavior is also observed in spiral, omega, and interlocking semi-circular shape passive micromixer designs in [23]. While all the three designs perform well beyond $\operatorname{Re}=1$, mixing efficiencies follow a decreasing trend with rising flowrates between $\operatorname{Re}=0.01$ and 1 . In the article [23], this is related to the short residence time of fluids and inadequate Dean vortices developed in curved microchannels. Although the overall channel length is around $22,000 \mu \mathrm{m}$ in the spiral micromixer design, mixing efficiencies vary between $65-70 \%$ for the Re number range of 0.01-1. Bhagat et al. [24] examined the effects of several obstruction geometries in the mixing channel of a Y-shape micromixer. While obstructed micromixer provides almost a complete fluid mixing at $\mathrm{Re}=0.01$ (measured at $\sim 5000 \mu \mathrm{m}$ axial distance), roughly $20 \%$ and $40 \%$ efficiency drop is observed at $\operatorname{Re}=0.1$ and 1 , respectively. Nonetheless, further increase of flowrate after $\operatorname{Re}=1$, which is defined as an inflection point in the study, increases the mixing performance by means of chaotic advection formed in the mixing channel. In our previous work [18], a similar inflection point was seen at $\operatorname{Re}=5$ after which the effective use of advection was accelerated in convex semi-circular ridge (CSCR) micromixer design. Although the CSCR micromixer geometry developed a complex flow profile even at very low flow conditions (e.g., $\operatorname{Re} \leq 5$ ), and hence enlarged the contact surface between fluids, short residence time of fluids reduced the diffusive activity across the interfacial area formed. Thus, a diminishing mixing efficiency profile was observed between $\operatorname{Re}=0.1$ and 5 .

In several other studies, researchers focused on improving fluid mixing specifically at very low Re numbers. Fang et al. [25] studied a T-shape passive micromixer with several baffle-embedded mixing units along a mixing channel. Numerical and experimental results showed that the design proposed increased mixing performance by inducing chaotic advection in mixing units at $\operatorname{Re}=0.29$. Based on the simulation and experimental outcomes, it was reported that 28-period mixing unit is required (i.e., $\sim 1.7 \mathrm{~cm}$ axial distance) to mix fluids completely. Ortega-Casanova and Lai [26] surveyed the effects of multiple inlets on mixing. The authors applied alternative inlet combinations on a passive micromixer design which has a single mixing unit similar to the one used in the study above [25]. Numerical outcomes show that increasing the number of inlets is more effective for the most 
challenging flow and transport conditions simulated in the study. When the effects of sevenand two-inlet configurations are compared, seven-inlet configuration increases mixing efficiency approximately 5.5 and 3.5 times for $\mathrm{Re}=0.29$ and 0.1 flow conditions, respectively. Mixing efficiencies quantified at the exit of the seven-inlet design (i.e., $\sim 5000 \mu \mathrm{m}$ axial distance) were reported as around $90 \%$ and $80 \%$ in $\mathrm{Re}=0.1$ and 0.29 flow cases, respectively. Lin et al. [21] proposed a 3-D circular passive micromixer design to generate vortex effects under low flow conditions. Using eight equally spaced inlets, a rotational fluid motion is created in the circular microchamber beyond a critical Re number that is 2.32 . While the mixing efficiency of the micromixer is around $50 \%$ and $74 \%$ at $\operatorname{Re}=0.5$ and 2.32 , respectively, more than $90 \%$ mixing values are obtained when $\operatorname{Re} \geq 4$ (measured at a $\sim 1000 \mu \mathrm{m}$ distance). Although vortex formation accelerated diffusive interaction between fluid bodies, high mixing efficiencies could also be reached as a result of using a relatively high molecular diffusion constant in the test cases, which is on the order of $10^{-7} \mathrm{~m}^{2} / \mathrm{s}$. Goullet et al. [27] surveyed fluid mixing in a classical T-shape micromixer under sinusoidal fluid injection conditions at $\operatorname{Re}=0.3$. Results indicate that sinusoidal injection of fluids forms sequential fluid segments in the mixing channel, which in turn enhance contact surface and diffusive mixing. The degree of mixing was reported as $38.4,70.3$, and $86.5 \%$ (measured at $500 \mu \mathrm{m}$ axial distance) for the injection frequencies of $1.25,5$, and $20 \mathrm{~Hz}$, respectively.

As discussed above, mixing performance can be boosted in virtue of complex flow patterns which are mostly generated at relatively high Re numbers. When, however, very low Re conditions are examined, a substantial decrease in mixing performance is seen because of yielding a small contact surface between fluids. This is mainly caused by ineffective flow manipulations in microchannels. Although some injection and design strategies help to improve mixing at low Re numbers, overall micromixer length can still rise to the centimeter level which is not desired as noted earlier. In the present paper, we propose a novel fluid overlapping passive micromixer design to surpass the small interfacial area restrictions at very low fluid flow conditions. Unlike the conventional micromixer configurations, where the effective use of advection process is prioritized to enlarge contact surface, the novel design proposed enables forming a predefined interfacial area between fluid bodies in a compact geometry. Therefore, a rapid inter-diffusion between fluids is ensured, and mixing distance is decreased significantly.

\section{Governing Equations and Mathematical Methods}

Computational Fluid Dynamics (CFD) simulations are performed to numerically describe the fluid flow and scalar transport in the micromixer. In all scenarios tested, it is assumed that the system is isothermal and gravitational effects are negligible. Fluids to be mixed are of constant density and viscosity, miscible, and non-reactive. Based on the assumptions above, flow field is simulated using incompressible Navier-Stokes (NS) and continuity equations as presented in Equations (1) and (2), respectively. Advection-diffusion (AD) equation is employed to resolve the scalar transport domain in the micromixer as given in Equation (3).

$$
\begin{aligned}
\rho\left[\frac{\partial \mathbf{u}}{\partial t}+\mathbf{u} \cdot \nabla \mathbf{u}\right] & =-\nabla p+\mu \nabla^{2} \mathbf{u} \\
\nabla \cdot \mathbf{u} & =0 \\
\frac{\partial c}{\partial t}+\mathbf{u} \cdot \nabla c & =D \nabla^{2} c
\end{aligned}
$$

where $\mu$ is the viscosity (Pa.s), $p$ is pressure $(\mathrm{Pa}), \rho$ is the density $\left(\mathrm{kg} / \mathrm{m}^{3}\right), \mathbf{u}=\left(\mathrm{u}_{\mathrm{x}}, \mathrm{u}_{\mathrm{y}}, \mathrm{u}_{\mathrm{z}}\right)$ is the velocity vector $(\mathrm{m} / \mathrm{s}), c$ is scalar concentration, and $D$ is molecular diffusion coefficient $\left(\mathrm{m}^{2} / \mathrm{s}\right)$.

Equations (1)-(3) are solved using OpenFOAM [28] (v5.0, OpenFOAM Foundation, OpenCFD Ltd., Bracknell, UK, 2015) CFD package, in which governing equations are discretized based on finite volume method (FVM). While simpleFOAM and scalarTransportFOAM solvers are employed to simulate steady-state incompressible fluid flow and 
passive scalar transport, respectively, a modified form icoFOAM solver is exploited in time-dependent solutions of coupled flow and scalar transport equations. Solvers are arranged to treat the advection and diffusion terms in the governing equations with secondorder accurate upwind [29] and central difference numerical schemes, respectively. In the simpleFOAM solver, SIMPLEC (semi-implicit method for pressure linked equationsconsistent) [30] algorithm is used to solve pressure-velocity coupling. To ensure stability in steady-state simulations, under-relaxation technique [31] is used with a factor of 0.9. Steadystate solutions are accepted to be converged when residuals reach $1 \times 10^{-6}$ threshold as typically practiced in several numerical micromixer studies [18,32,33]. In time-dependent simulations, temporal terms are discretized using Crank-Nicolson scheme with a blending coefficient of 0.9 .

Dimensionless Reynolds ( $\mathrm{Re}$ ) and Peclet $(\mathrm{Pe})$ numbers are used to determine the characteristics of fluid flow (e.g., laminar or turbulent) and scalar transport (e.g., advectionor diffusion-dominant) in the micromixer, respectively. Re and Pe numbers are computed in the exit channel of the micromixer as defined in Reference [34]. In the present study, flowrate-averaged mixing approach [33] is employed to quantify the degree of mixing on a given plane as formulized in Equation (4). Unmixed and fully mixed conditions are specified in a mixing index (MI) scale between 0 and 1, respectively. It should be noted that computing a mixing efficiency only relying on the scalar concentration distribution on a certain cross-section may provide imprecise mixing outcomes in cases where the distribution of scalar concentration is non-uniform in a flow profile. More information on this point can be found in References [18,33].

$$
M I=1-\sqrt{\frac{\sigma^{2}}{\sigma_{\max }^{2}}}, \sigma^{2}=\frac{\int_{A}(c-\bar{c})^{2} \cdot u d A}{\int_{A} u d A}, \bar{c}=\frac{\int_{A} c \cdot u d A}{\int_{A} u d A}
$$

where $A$ is area, $u$ is velocity, $\sigma$ and $\sigma^{2}$ are variance and the maximum variance, respectively, $c$ is concentration, and $\bar{c}$ is the average concentration. In grid independence tests, Equation (5) is used to measure numerical discrepancy between a mesh density and the finest mesh for a given parameter.

$$
\Delta D_{M-F}=\left|\frac{P_{M}-P_{F}}{P_{F}}\right| \times 100
$$

where $P_{M}$ and $P_{F}$ denote the parameter values, obtained from the numerical solutions of a certain mesh density and the finest mesh, respectively. $\Delta D_{M-F}$ shows the difference, as a percentage, between a mesh level and the finest mesh with respect to the parameter employed. In this research, pressure drop $(\Delta p)$ and mixing efficiency (MI) parameters are used to assess numerical errors in fluid flow and scalar transport simulations, respectively.

\section{Micromixer Design and Simulation Setup}

In this study, a 3-D circular-shaped fluid overlapping (CSFO) passive micromixer is developed. As shown in Figure 1, the micromixer geometry consists of three main branches that are inlet channel, mixing units, and exit channel. The dimensions of the circular inlet and exit channels are equal with a length $\left(l_{i}\right.$ and $\left.l_{e}\right)$ and cross-section area $\left(A_{c}\right)$ of $200 \mu \mathrm{m}$ and $2 \times 10^{4} \mu \mathrm{m}^{2}$, respectively. In the CSFO design, five identical mixing units are used to observe the effect of fluid overlapping approach in a wide range of flow conditions. The height $\left(h_{u}\right)$ and radius $\left(r_{u}\right)$ of a single mixing unit are $60 \mu \mathrm{m}$ and $300 \mu \mathrm{m}$, respectively. Each mixing unit is divided equally in the z-direction with a solid, impermeable, and thin-plate disk element which is coaxial with the mixing unit and has a radius $\left(r_{d}\right)$ of $270 \mu \mathrm{m}$. It is assumed that the existence of physical joining parts between a disk element and mixing unit will affect the overlapping flow pattern trivially. Therefore, for the sake of designing convenience in the present study, these parts are excluded in the CSFO geometry. In physical applications of the CSFO design, the disk elements can be attached to mixing units from various points as indicated by the line arrows I, II, and 
III in Figure 1. Other than that, the mixing units are linked to each other via cylindrical extensions, of which height $\left(h_{c}\right)$ is $10 \mu \mathrm{m}$ and radius $\left(r_{c}\right)$ is equal to that of inlet and outlet channels. Nonetheless, it should be noted that the purpose of including these connection parts is only to be able to measure mixing performance at the outlet of the mixing chambers. In a physical design, these extensions can be omitted since the short residence time of fluids in these sections will contribute to diffusive mixing negligibly. The dimensions of the CSFO micromixer were selected consistent with the 3-D passive micromixer designs studied in the literature. The 3-D CSFO passive micromixer proposed can be fabricated using the current microfabrication technology. Multi-layer fabrication methods [35,36] can be used in physical construction of the CSFO design. Example micromixer studies may be seen in References [21,37-39] for detailed fabrication process of 3-D geometries at microscales.

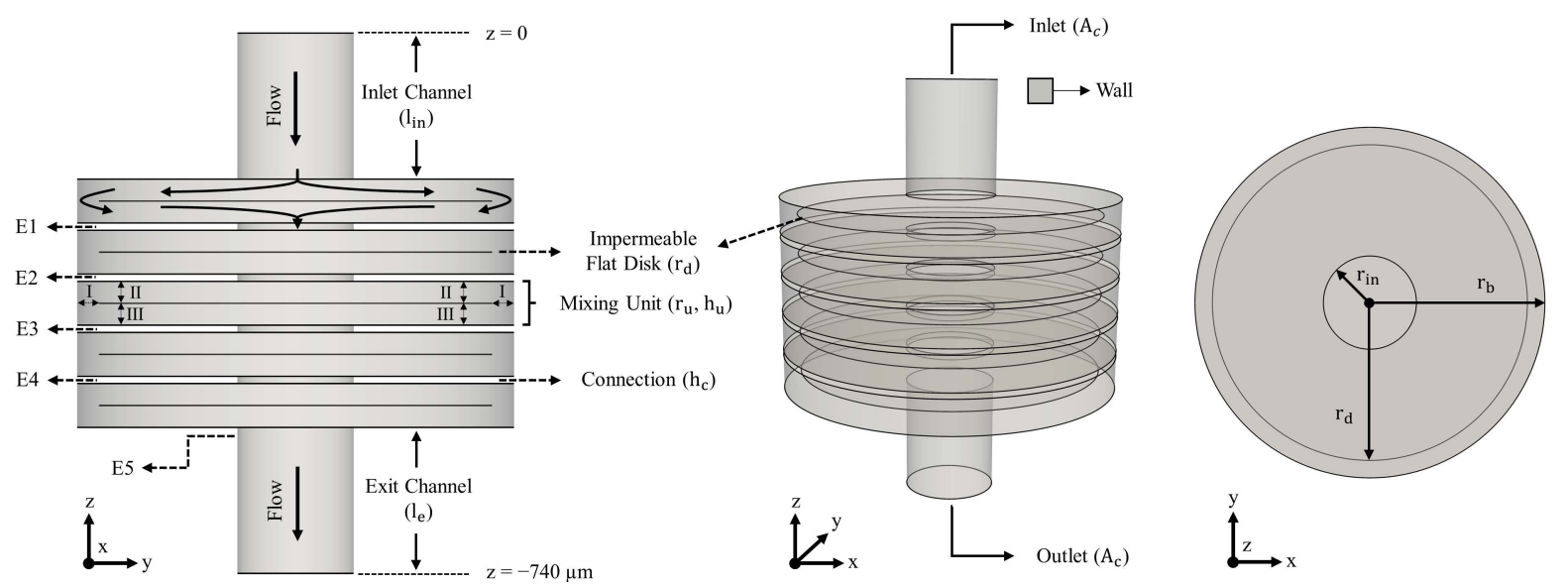

Figure 1. Different views of the 3-D CSFO micromixer geometry. E1, E2, E3, E4, and E5 are the locations $5 \mu \mathrm{m}$ after the exit of each mixing box.

In the CSFO micromixer, nested-type inlets are used to create overlapping flow profile throughout the disk surfaces in mixing units. The core and outer segments of inlet surfaces are used to inject fluids as depicted in Figure 2. Please note that these segments have an equal surface area in all injection types applied, and these surfaces are further split equally in injection $\mathrm{B}$. The development of different injection patterns in both circular and rectangular geometries can be seen from Figures A1 and A2 in Appendix A. In the present study, both symmetrical and alternating injection patterns (see Figures 2 and A2) are applied over the inlet boundary.

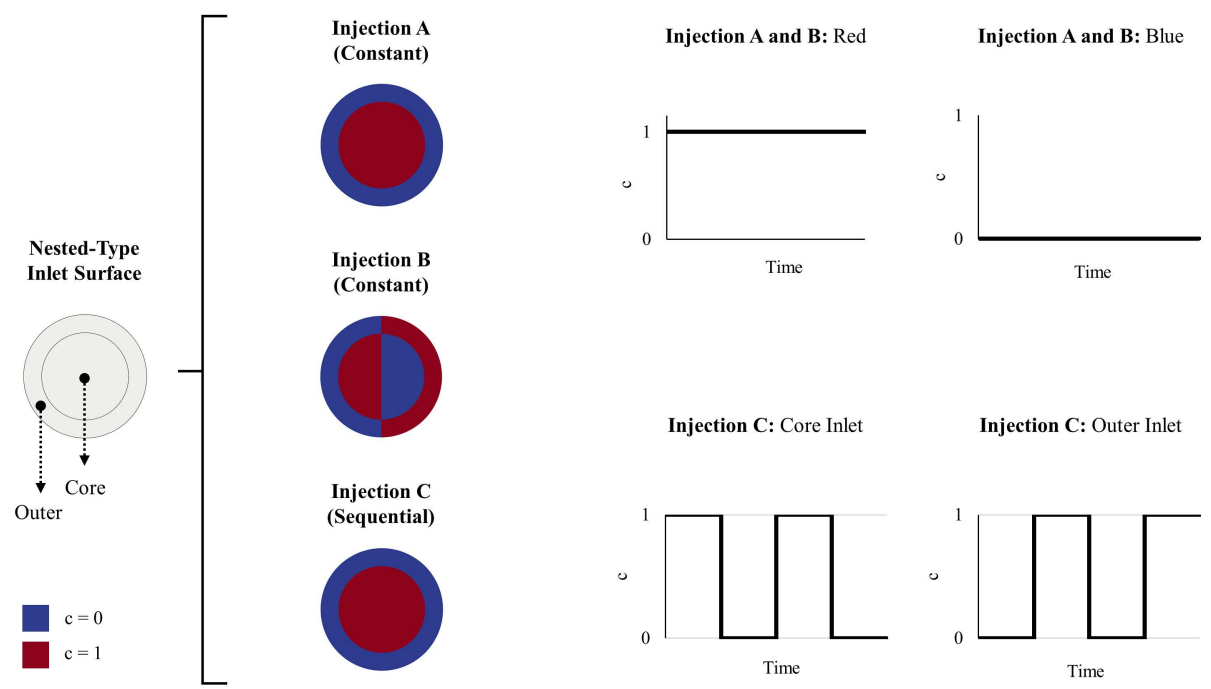

Figure 2. Fluid injection types applied over the inlet boundary of the CSFO micromixer design. 
Micromixer performance is examined extensively establishing several molecular diffusion constants, i.e., $\mathrm{D}_{1}=3.0 \times 10^{-10}$ (crystal violet dye in water [40]), $\mathrm{D}_{2}=1.5 \times 10^{-9}$ (fluorescein solution in water [41]) and $\mathrm{D}_{3}=3.0 \times 10^{-9} \mathrm{~m}^{2} / \mathrm{s}$ (self-diffusion coefficient of water [42]), in a broad range of flow conditions that are $\operatorname{Re}=0.1,0.5,1,5$, and 10. In all mixing scenarios, equal amount of fluid is injected from each inlet segment in injection $\mathrm{A}, \mathrm{B}$, and C. The physical properties of mixing fluids are chosen close to that of water at $20^{\circ} \mathrm{C}[43,44]$ with a density $(\rho)$ and viscosity $(\mu)$ of $10^{3} \mathrm{~kg} / \mathrm{m}^{3}$ and $10^{-3} \mathrm{~Pa} \cdot \mathrm{s}$, respectively. To solve the governing flow equations, the following boundary conditions are prescribed in numerical simulations: a uniform velocity profile at the inlets, zero-gauge pressure at the outlet, and zero fluid velocity, i.e., no-slip condition, on solid surfaces. In scalar transport simulations, the gradient of scalar concentration is set to zero at the outlet and solid boundaries to prevent the scalar undergo diffusion over these surfaces. To investigate fluid mixing in the micromixer, relative scalar concentrations, 0 and 1, are imposed on the inlet surface as described schematically in Figure 2. In injection A and B cases, fluid injection is constant over time, and therefore numerical simulations are conducted in two steps as follows. First, a steady-state flow domain is obtained from the simultaneous solution of Equations (1) and (2). Second, a steady-state passive scalar transport simulation is performed by solving the $\mathrm{AD}$ equation with the stationary flow domain obtained. In injection $C$, fluids are injected over the core and outer inlet regions as a square wave with the same injection frequency (f). Thus, a time-dependent simulation is carried out to solve coupled fluid flow and scalar transport equations. In transient simulations, overall simulation times were chosen long enough — for a given flow condition, at least three times of the theoretical fluid mean residence time in the micromixer-to observe the complete development of fluid mixing in the micromixer. In the rest of the paper, CSFO-A, $-\mathrm{B}$ and - $\mathrm{C}$ notations are used to describe the CSFO micromixer configurations with fluid injection modes A, B and C, respectively. Before the numerical simulations of the test scenarios, the CFD code was validated against the experimental data of two different T-shaped passive micromixer studies in References [45,46]. The validation outcomes, given in Figure A3 in Appendix A, indicate that numerical simulation results are in a good agreement with the experimental data reported in both studies. Thus, the numerical method presented above can be used to predict the mixing performance of the CSFO micromixer proposed.

\section{Mesh Study}

Numerical solution of advection-dominant transport systems is prone to create high amount of numerical (or false) diffusion errors [34,47]. This is due to inaccurate approximation of steep scalar gradients that inherently develop at high Pe transport conditions. In FVM, maintaining an orthogonality between flow and grid boundaries is pivotal to minimize numerical diffusion. For further information about managing numerical errors in high Pe transport systems, see References [34,47-49]. In this research, hexahedron elements are used to discretize the computational domain in numerical simulations. A systematic mesh study is performed by determining four different grid levels in the computational domain of the CSFO micromixer. Total element numbers in L1, L2, L3, and L4 grid levels are $3.90 \times 10^{6}, 2.45 \times 10^{6}, 1.58 \times 10^{6}$, and $1.05 \times 10^{6}$, respectively. Numerical simulations are carried out for the highest Pe number scenario examined in the CSFO-B micromixer configuration (i.e., $\mathrm{Pe}=3.33 \times 10^{4}$ when $\mathrm{Re}=10$ and $\mathrm{D}=\mathrm{D}_{1}=3.0 \times 10^{-10} \mathrm{~m}^{2} / \mathrm{s}$ ). Mesh study outcomes are presented in Figure A4a-c in Appendix A.

Figure A4a shows that there is a good agreement between the finest and coarser mesh levels when the pressure drop is used to quantify the relative numerical errors in numerical solutions. The maximum variation is calculated as $2.1 \%$ between L1 and L4 meshes which evidently indicates that even the coarsest grid level, L4, can provide quite accurate results in fluid flow simulations. The same agreement between different mesh level solutions is also seen in Figure A4b, which shows the distribution of velocity along the diameter of outlet plane. On the contrary, when outlet mixing efficiency is employed in error analysis, numerical solutions exhibit a high divergence as indicated by the rising 
trendline in Figure A4a. In fact, such a discrepancy between the two trendlines occurs due to quite different transport conditions in fluid flow and scalar transport simulations. While a mild $\operatorname{Re}$ number $(\operatorname{Re}=10)$ in the former offers a better control of numerical errors even in relatively coarse grids, the latter is carried out at a very high Pe number $\left(\mathrm{Pe}=3.33 \times 10^{4}\right)$. Hence, much smaller mesh elements are required to approximate sharp scalar gradients accurately. Accordingly, mesh study outcomes need to be evaluated in refence to scalar transport simulations to employ a suitable mesh density in the simulations. For the MI parameter given in Figure A4a, the differences in L1-L4, L1-L3, and L1-L2 comparisons are measured to be nearly 28,13 , and $2.7 \%$, respectively. The lessening percentages indicate that false diffusion generation is suppressed noticeably with increasing mesh densities. The convergent trend of mesh refinement can also be seen in Figure A4c, which shows the development mixing efficiency along the CSFO micromixer for all mesh levels tested. Considering the small variation, i.e., $2.7 \%$, against a large mesh density difference, i.e., $1.45 \times 10^{6}$ elements, between L1-L2 mesh levels, L2 mesh level is determined to conduct numerical simulations. Furthermore, this selection is also validated by estimating an effective diffusivity coefficient from the scalar transport solution of L2 mesh level as proposed in [48]. The ratio of effective diffusivity coefficient to molecular diffusion constant was found to be 1.112 which is quite close to 1 . This implies that the molecular diffusion constant simulated is mostly recovered from the numerical solution and the amount of numerical diffusion errors is trivial. Therefore, the use of L2 mesh density provides mostly physical mixing outcomes even in the worst-case scenario. Please note that in other mixing scenarios established in the present paper, numerical solutions will generate much less numerical diffusion due to diminishing magnitude of Pe number in mild transport conditions.

\section{Results}

\subsection{Fluid Mixing in the CSFO-A and CSFO-B Micromixer Configurations}

At small Re numbers, ineffective manipulation of fluid bodies cause yielding a small contact area between fluid bodies, which in turn limits mixing by diffusion. To overcome this problem and enlarge the interfacial area between mixing fluids, a typical approach is to create several laminations in microchannels [38]. In this method, the main flows are divided into numerous sub-streams or layers of fluid sections which are aligned in microchannels to be in serial or parallel flow regions. In laminating micromixers [37,50-52], the overall contact surface is proportional to the number of different fluid segments generated in the micromixer. Although diffusive mixing is promoted over the interfacial area shared by the fluid segments, usually a complex channel network is required to align fluids in microchannels. In the CSFO micromixer design proposed, the enhancement of contact area is ensured without generating multiple flow sectors in the flow domain. Instead, entire fluid bodies are overlapped and stretched in compact mixing units. As can be seen from Figure A5 in Appendix A, which shows the flow pathlines and 3-D flow domain in the CSFO micromixer, fluids that are injected from core and outer inlet segments flow concentrically through the inlet channel and are stretched over the disk surface. During the fluid flow in the CSFO micromixer, the injected fluids occupy different volumes of the flow domain. As the core flow (shown in red in Figure A5) follows a path around disk elements at the central region of the micromixer, the outer flow (shown in blue in Figure A5) develops between the core flow and micromixer walls. Therefore, a quite large interfacial area is yielded between the two fluid bodies due to the encapsulation of the core flow by the outer flow across the CSFO micromixer domain. The development of contact surface in both upper and lower compartments of a single mixing unit is shown schematically in Figure 3. 


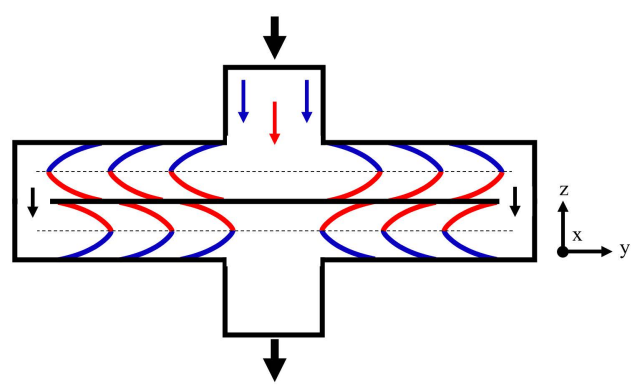

(a) Constant fluid injection (CSFO-A)

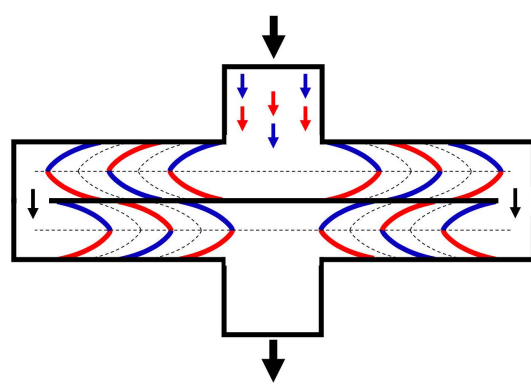

(c) Sequential fluid injection $(\mathrm{CSFO}-\mathrm{C})$

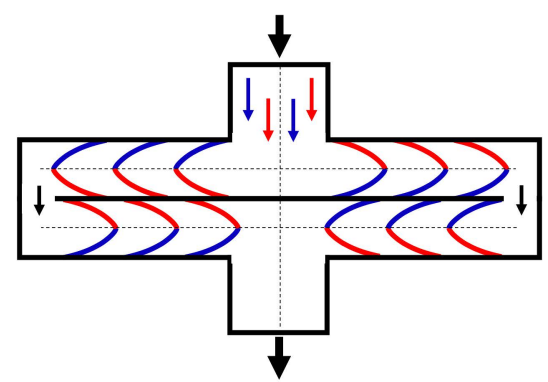

(b) Constant fluid injection (CSFO-B)

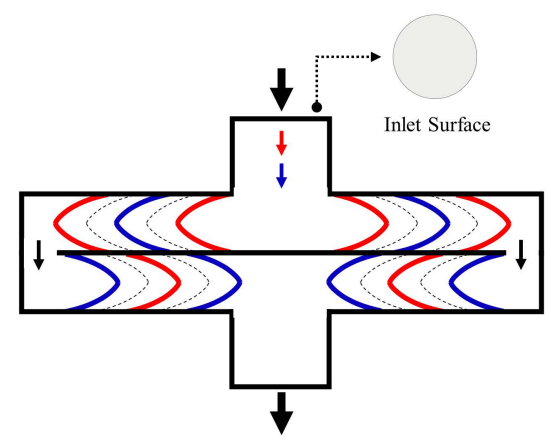

(d) Sequential fluid injection over the entire inlet surface

Figure 3. The distribution of injected fluids in each mixing unit of the micromixer configurations (a) CSFO-A; (b) CSFO-B; and (c) CSFO-C. (d) The distribution of fluids in a single mixing unit when the entire inlet surface is used to inject fluids sequentially. The dashed lines and curves show the contact surfaces formed between different fluids. Red and blue colors represent the mixing fluids injected from inlet surface(s). Black arrows show flow direction.

As shown in Figure 3 the overlapping (or stratified) fluid pattern expands throughout the disk surface in the upper volume of mixing chamber and flows to the lower volume through the gap between the mixing chamber and the disk element. In the lower section, the above streams are converged at the exit of the cylindrical box and transferred to the next mixing unit. In all design configurations, the same flow cycle is repeated until the fluids are conveyed to the main exit channel of the micromixer. While both CSFO-A and CSFO-B configurations develop a contact surface on the horizontal plane, CSFO-B micromixer also forms an interface in the vertical direction due to alternating fluid injection imposed on the core and outer inlet segments. The horizontal and vertical contact areas formed between mixing fluids are represented by the dashed lines in Figure 3. Meanwhile, it should be noted that the total area of the gap region is approximately 2.7 times higher than that of exit cross-sections. Thus, the fluid flow is not restricted in the gap region and the residence time of fluid particles in a single mixing unit is controlled by the area of the exit cross-section. In the present CSFO micromixer design, the surface area of inlet, outlet, and exit planes are kept equal as noted earlier.

When the mixing performance of micromixers are measured, the outcomes evidently show that diffusive mixing - in the vertical direction - is activated across the large interfacial areas formed. Figure A7 in Appendix A shows the development of fluid mixing along the CSFO-A and CSFO-B micromixers for all mixing conditions tested. Firstly, regarding the results in Figure A7, it can be said that the vertical contact surface formed in the CSFO-B micromixer affects the mixing performance trivially. The MI values of both configurations indicates that even the maximum difference is less than $5 \%$. This is because the degree of mixing is mainly controlled by the horizontal surface areas developed in the upper and lower sections of mixing boxes. The contribution of the additional interface to the diffusive mixing - in the horizontal direction-is more visible at low flow conditions, whereas this effect vanishes by lessening residence time of fluid particles at higher Re numbers. In the lowest flow condition $(\operatorname{Re}=0.1)$, almost a complete fluid mixing $(\mathrm{MI}>94 \%)$ 
is observed at the exit of the first mixing unit. Moreover, although it is not reflected in the plots, the distribution of scalar concentration in simulation results showed that the biggest portion of the mixing takes place only in the upper section of the first mixing box. In all molecular diffusion scenarios, more than $90 \%$ mixing efficiency is yielded in a distance less than $260 \mu \mathrm{m}$ in the main streamwise direction. At $\operatorname{Re}=0.5$, while at least two mixing units are required to provide more than $90 \%$ mixing value when the smallest diffusion constant is used, this is not the case in higher diffusivity conditions. In $\mathrm{D}_{2}$ and $\mathrm{D}_{3}$ mixing scenarios, more than $94 \%$ mixing efficiency is obtained at the exit of the first mixing unit of the CSFO-A micromixer. As can be pursued from the change of the trendlines in increasing Re numbers, reducing contact time between fluid bodies suppresses the inter-diffusion continually. Hence more mixing units are required to enhance the degree of mixing in the micromixer. Notably, the combination of low contact times with small diffusion coefficients develops the most challenging mixing conditions in the micromixer. At $\operatorname{Re}=1$, while $\mathrm{D}_{2}$ and $\mathrm{D}_{3}$ diffusivities can still be tolerated against the fluid residence time reduced, the use of the smallest diffusion constant becomes difficult. In that case, the mixing distance increases to $400 \mu \mathrm{m}$ (E3) and $470 \mu \mathrm{m}$ (E4) to obtain nearly $86 \%$ and $93 \%$ MI, respectively. In all mixing scenarios tested, the lowest mixing efficiencies are obtained for the two highest flow conditions of the $D_{1}$ case as expected. The MI values at the exit of the micromixers are found to be nearly $65 \%$ and $54 \%$ for $\operatorname{Re}=5$ and 10 , respectively. As mentioned previously, although the contact surface area is increased substantially in CSFO geometry, the development of mixing by diffusion is prohibited by rising flowrates. Nonetheless, the MI values are still promising for the higher molecular diffusion constants, $\mathrm{D}_{2}$ and $\mathrm{D}_{3}$, as shown in Figure A7. At $R e=5$, while $D_{2}$ scenario provides more than $86 \%$ mixing efficiency at the exit of the third mixing unit (E3), only two units are required to reach a MI value of nearly $91 \%$ (E2) in $\mathrm{D}_{3}$ case. For the same diffusivity scenarios, $\mathrm{D}_{2}$ and $\mathrm{D}_{3}$, the highest flow condition, $\mathrm{Re}=10$, yields $84 \%$ and $92 \%$ fluid mixing at E5 and E4 exits, respectively. For all mixing conditions examined, the distribution of scalar concentrations on the outlets of CSFO-A and CSFO-B micromixers are presented in Figure 4. In addition, for the smallest diffusion constant, $\mathrm{D}_{1}$, the development fluid mixing on different cross-sections along the CSFO-A configuration can be seen from Figure A6 in Appendix A.

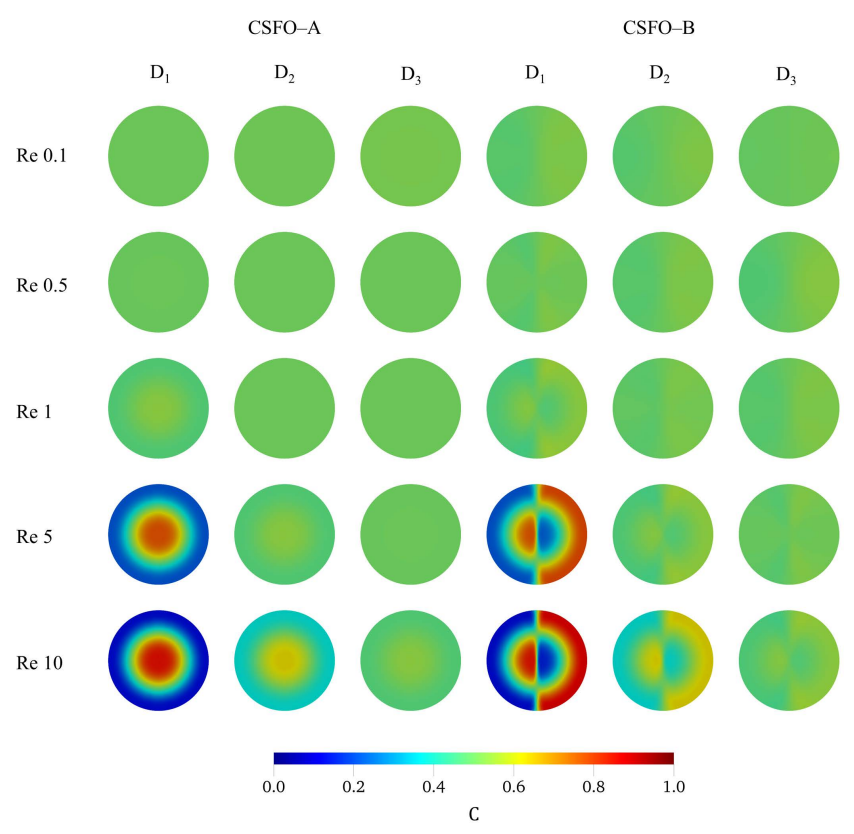

Figure 4. The distribution of scalar concentrations on the exit cross-section of the CSFO-A (first three columns on the left) and CSFO-B (last three columns on the right) micromixer configurations. 


\subsection{Fluid Mixing in the CSFO-C Micromixer Configuration}

As discussed above, when the CSFO micromixer is operated with constant fluid injection, large contact surfaces are yielded between fluid bodies in the horizontal directions. However, in the CSFO design, the overall interfacial area can be enhanced further if the fluids are injected sequentially over the core and outer inlet segments as described in Figure 2. Sequential or pulse injection of fluids can be achieved by manipulating micropumps as described and used in References [53-56]. In the case of sequential injection in CSFO-C configuration, the development of additional contact areas between consecutive fluid pairs is enabled as shown schematically in Figure $3 c$ (see the dashed curves). In mixing units, these new interfaces move dynamically by expanding and shrinking in the upper and lower mixing sections, respectively, which creates a wave pattern throughout the disk surfaces. Therefore, in each half volume of the mixing units, diffusive mixing is also promoted in the horizontal directions. It should be noted that unlike the CSFO-A and CSFO-B configurations, where entire fluid bodies are overlapped on the horizontal plane, in the CSFO-C micromixer, different fluid segments develop the overlapped fluid structure due to wave pattern in the horizontal direction. The mixing performance of the CSFO-C configuration is investigated in various injection frequencies-between 10 and $250 \mathrm{Hertz}(\mathrm{Hz})$ depending on the flow condition-for the most challenging mixing scenarios (i.e., $\mathrm{D}=\mathrm{D}_{1}$ and $\operatorname{Re}=1$, 5 , and 10). The evolution of mixing efficiencies is observed with respect to time at the exit of each mixing unit. The results are plotted in Figure A8 in Appendix A. Please note that in Figure $\mathrm{A} 8, \mathrm{f}=0 \mathrm{~Hz}$ plots show time-dependent numerical solutions of $\mathrm{CSFO}-\mathrm{A}$ micromixer, in which fluid injection is constant over time as described in Section 3 and Figure 2. These solutions are used to compare the relative effects of constant and sequential fluid injections in the CSFO design.

Figure A8 evidently shows that the formation of additional contact surface areas accelerated diffusive mixing substantially. At $\operatorname{Re}=1$, even the lowest injection frequency, $\mathrm{f}=10 \mathrm{~Hz}$, is adequate to reduce the mixing distance (MI >90\%) to the exit of the second mixing unit (E2). However, further increase of the injection frequency contributes to the overall mixing efficiency slightly. When the mixing outcomes are compared with that of CSFO-A micromixer, CSFO- $\mathrm{C}$ configuration $(\mathrm{f}=10 \mathrm{~Hz})$ provides a rapid fluid mixing over a very short distance. To reach a MI value around $85 \%$, the time and distance required are "240 millisecond (ms) and $330 \mu \mathrm{m}$ " and "640 ms and $400 \mu \mathrm{m}$ " in CSFO-C and CSFO-A configurations, respectively. Therefore, the use of sequential injection reduces mixing time and distance by the factors of 2.7 and 1.2, respectively. Much higher improvements in mixing values are seen in $\operatorname{Re}=5$ and 10 flow conditions as indicated by the rising trendlines in Figure A8. Meanwhile, it needs to be explained that before reaching their steady values, the mixing efficiencies follow a declining and rising trend after a sharp increase at early stages. The spikes in the trendlines are observed at the exit of each mixing unit in both CSFO-A and CSFO-C micromixer configurations. These peak points essentially occur due to the following reason explained. At the beginning of the fluid flow in the inlet channel, the formation parabolic flow profile yields a relatively high contact area and diffusive mixing starts developing on this surface. During the fluid flow, the diffusive mixing on the parabolic front travels in the micromixer and leaves the micromixer in the end. Therefore, the peak mixing efficiency, which is generated at the very early stage, is observed at the exit of the mixing units. After the peak values of MI, the declining and rising trends show the actual development of mixing efficiency in the micromixers.

At $\operatorname{Re}=5$, as constant fluid injection $(\mathrm{f}=0 \mathrm{~Hz})$ can only offer a MI value around $63 \%$ $(\mathrm{t}=280 \mathrm{~ms})$ at E5 location, more than $85 \% \mathrm{MI}(\mathrm{t}=120 \mathrm{~ms})$ is obtained at the exit of the second mixing unit (E2) by the use of sequential fluid injection in the CSFO geometry $(\mathrm{f}=25 \mathrm{~Hz})$. For higher injection frequencies, $\mathrm{f}=50$ and $100 \mathrm{~Hz}$, the degree of mixing rises to $95 \%(t=160 \mathrm{~ms})$ and $98 \%(t=180 \mathrm{~ms})$ levels at the same location (E2), respectively. Unlike the $\operatorname{Re}=1$ flow condition, the effect of injection frequency is more visible at $\operatorname{Re}=5$. While $\mathrm{f}=25 \mathrm{~Hz}$ case provides nearly $65 \%(\mathrm{t}=140 \mathrm{~ms})$ mixing efficiency at the exit of the first mixing box (E1), the MI values reach $81 \%(t=120 \mathrm{~ms})$ and $90 \%(t=100 \mathrm{~ms})$ levels 
in $\mathrm{f}=50$ and $100 \mathrm{~Hz}$ scenarios, respectively. In the highest flow scenario, $\operatorname{Re}=10$, while nearly 53\% MI ( $\mathrm{t}=140 \mathrm{~ms})$ can be measured at the last exit location (E5) of the CSFO-A micromixer, CSFO-C configuration provides more than $61 \% \mathrm{MI}(\mathrm{t}=70 \mathrm{~ms})$ at the exit of the first mixing unit (E1) for the lowest injection frequency tested ( $f=50 \mathrm{~Hz})$. When the injection frequency is set to $\mathrm{f}=100$ and $250 \mathrm{~Hz}$, the MI value reaches $77 \%(\mathrm{t}=80 \mathrm{~ms})$ and $88 \%(t=100 \mathrm{~ms})$ on the same exit location (E1), respectively. As the best-case scenarios at $\operatorname{Re}=5(\mathrm{f}=25 \mathrm{~Hz})$ and $\mathrm{Re}=10(\mathrm{f}=50 \mathrm{~Hz}), \mathrm{CSFO}-\mathrm{C}$ configuration develops approximately $85 \%(t=120 \mathrm{~ms})$ and $83 \%(t=70 \mathrm{~ms})$ mixing efficiencies in a distance less than 330 and $400 \mu \mathrm{m}$, respectively. When these mixing figures are compared with the outputs of the CSFO-A configuration, mixing conditions are improved significantly in terms of efficiency, distance, and time. Notably, such an improvement could be achieved by means of the extra contact areas formed between consecutive fluid segments during the sequential injection.

\section{Discussion}

The CSFO micromixer and nested-type inlets developed in this study offer a novel design approach to mix fluids at microscales. Unlike the conventional micromixer designs, where the enhancement of interfacial area strongly depends on the effective manipulation of fluid flow in microchannels, the CSFO geometry inherently develops a large contact area without requiring a complex flow formation in the micromixer domain. Therefore, better operating conditions are obtained. As can be seen from Figure A4d, the CSFO design improves fluid mixing under reasonable pressure drop conditions. Even the highest flow condition, $\operatorname{Re}=10$, yields a pressure drop value of less than $1.4 \mathrm{kPa}$, which is quite acceptable compared to that of reported in the literature $[57,58]$. The pressure values in Figure A4d can be decreased further when the number of mixing units are reduced in the design. When the mixing performance of the CSFO micromixer is compared with other studies in the literature, a substantial amount of mixing efficiency is achieved over a very short distance as presented in Table 1.

Table 1. The comparison of the CSFO-A configuration with the micromixers reported in the literature in terms of mixing performance in low flow conditions $(\operatorname{Re}<10)$.

\begin{tabular}{|c|c|c|c|c|}
\hline Micromixer & $\operatorname{Re}$ & Mixing Efficiency (\%) & Mixing Length $(\mu \mathrm{m})$ & Reference \\
\hline Crossing Channels & 0.1 & 88 & 6400 & [57] \\
\hline Multi-Inlet & $0.1-0.29$ & $90-80$ & 5000 & [26] \\
\hline Serpentine & 0.2 & 100 & 7500 & [59] \\
\hline Baffled & 0.29 & 52 & 7200 & [25] \\
\hline T-Shaped $(\mathrm{f}=20 \mathrm{~Hz})$ & 0.3 & 86.5 & 500 & [27] \\
\hline T-Shaped (split inlet) & 0.5 & 42 & 2000 & [18] \\
\hline Vortex & 0.5 & 50 & 1000 & [21] \\
\hline Rhombic & 1 & 55 & 6000 & [58] \\
\hline \multirow[t]{2}{*}{ Obstructed Channels } & 1 & 55 & 1180 & [60] \\
\hline & 0.1 & 94 & 260 & \\
\hline \multirow{2}{*}{ CSFO-A $\left(\mathrm{D}_{1}\right)$} & 0.5 & 94 & 400 & Present study \\
\hline & 1 & 91 & 470 & \\
\hline
\end{tabular}

It should also be noted that the use of nested-type inlets is not only limited to the CSFO micromixer, but also can be used in any type of active or passive micromixer designs. Concentric flows that are developed in nested-type inlets basically provide two main advantages. First, when the fluids are injected concentrically, the deformation of fluid bodies in the micromixer becomes relatively much easy compared to the conventional fluid injections in separate channels. For instance, in split-and-recombination (SAR) micromixers $[43,61,62]$, several mixing units are required to increase the distribution of inlet streams in sub-channels. When, however, fluids are injected concentrically, the distribution ratio of different fluids in the sub-channels is increased, and hence the number of mixing units required can be reduced. Second, the nested-type inlets inherently create a contact area between the two fluids being injected. Thus, fluid mixing is initiated at the beginning 
of the inlet channel before fluids reach to the micromixer. The test simulations, which we do not report here, showed that the use of concentric flows in circular or rectangular channels improves diffusive mixing significantly when $\mathrm{Re} \leq 0.1$. Therefore, in extremely slow flow conditions, only a straight or curved channel with a nested-type inlet can be used as a micromixer.

The CSFO micromixer can also function without employing the nested-type inlets when the fluid injection is sequential. In such a case, the entire inlet surface is used to feed the micromixer with different fluids sequentially. However, in this condition, the interfacial area on the horizontal plane is not formed and the overall contact surface is developed by the wave pattern as described schematically in Figure A4d. Besides this function, the CSFO geometry can be modified to be operated at much higher flow conditions by generating chaotic advection in the micromixer. For this purpose, the disk elements can be redesigned with alternative grooves or obstacles to create complex flow patterns in the mixing units.

In addition to the circular micromixer design, the fluid overlapping mixing approach can also applied in rectangular or polygonal (e.g., pentagon, hexagon, etc.) geometries. However, when a rectangular geometry is used, a non-uniform velocity distribution can develop on the rectangular plane that divides mixing box volume equally. As displayed in Figure 5 which shows the flow pathlines and the distribution of flow vectors in singlemixing-box circular and square designs $(\operatorname{Re}=10)$, the two geometries render varying flow profiles. In contrast to smooth flow distribution in the circular design, the fluid flow is dominated at the center of the horizontal directions in the square geometry, which creates dead flow zones at the corner regions of the square box (see the dashed red lines). Although that variation in the flow structure does not affect the development of the fluid overlapping pattern in the mixing box, the diffusive interaction is diminished. That is due to the yield of a relatively a smaller contact area and increased flow velocity in central directions, which reduces contact time. Regarding the outcomes in Figure 5, the circular geometry appears to be an optimal shape for the fluid overlapping mixing approach.
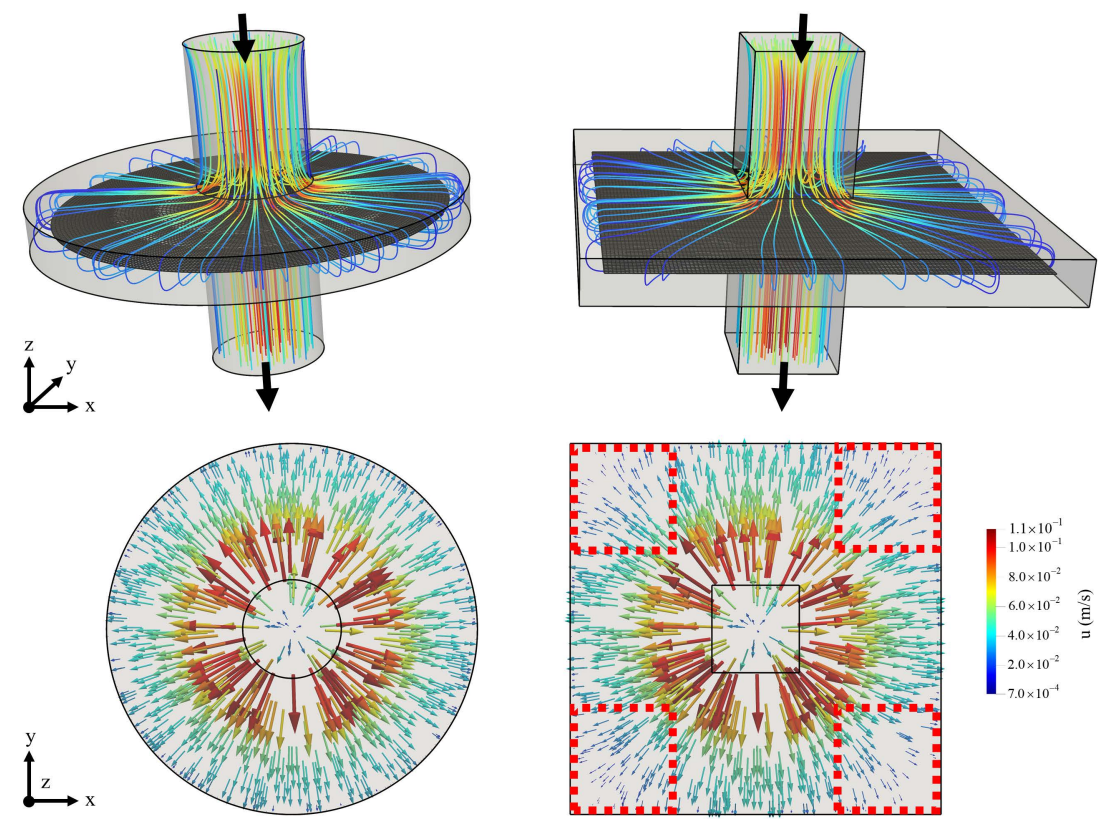

Figure 5. The distribution of flow vectors and flow pathlines in single-mixing-box circular (left) and square (right) fluid overlapping design configurations $(\operatorname{Re}=10)$. Black arrows show flow direction.

Consequently, considering the plain design structure and high mixing performance, the CSFO passive micromixer can be integrated with microfluidic systems or used as a stand-alone device to mix fluids at microscales. 


\section{Conclusions}

In this research, fluid overlapping mixing approach and nested-type inlets are introduced for passive micromixers. A 3-D circular-shaped passive micromixer design is developed to enhance fluid mixing particularly at low flow conditions that is $\operatorname{Re}<10$. The mixing performance of the CSFO micromixer is examined numerically in various fluid flow and molecular diffusion conditions. The effects of alternative design configurations and injection strategies are tested. Numerical simulation results indicate that the CSFO design creates a large contact surface between mixing fluids in both upper and lower volumes of each mixing unit. In the case of constant fluid injection, the overlapping fluid pattern develops an interfacial area throughout the disk elements on the horizontal plane. However, when the fluids are injected sequentially, additional contact areas are formed between consecutive fluids. While symmetrical and alternating fluid feeding types provide almost identical results in the constant injection scenarios, the mixing effect of injection frequency is increased with rising Re numbers in the sequential injection cases. In both injection conditions, high mixing efficiency values could be achieved with a reasonable pressure drop in the CSFO micromixer. The maximum pressure drop is found to be less than $1.4 \mathrm{kPa}$ at $\operatorname{Re}=10$. For the smallest diffusion coefficient and constant fluid injection, more than $90 \%$ mixing efficiency is quantified in a distance of 260,400 , and $470 \mu \mathrm{m}$ for $\operatorname{Re}=0.1,0.5$, and 1 flow scenarios, respectively. The mixing distances are reduced further even in high flow conditions when fluids are injected sequentially. When the mixing outcomes are compared with that of reported in the literature, the CSFO design offers a high amount of fluid mixing over a very short distance. Therefore, the CSFO micromixer can be employed in next generation microfluidic systems, where short mixing distances will be required, to mix fluids at microscales.

Author Contributions: Both authors contributed to the development of micromixer design, analysis and discussion of the results, and the preparation of the paper. M.B.O. contributed to setup and completion of the numerical simulations. M.M.A. edited the paper and supervised the overall research. Both authors have read and agreed to the published version of the manuscript.

Funding: This research received no external funding.

Institutional Review Board Statement: Not applicable.

Informed Consent Statement: Not applicable.

Data Availability Statement: Data is contained within the article.

Acknowledgments: This research did not receive any grants from funding agencies in the public, commercial, or not-for-profit sectors.

Conflicts of Interest: The authors declare no conflict of interest. 


\section{Appendix A}

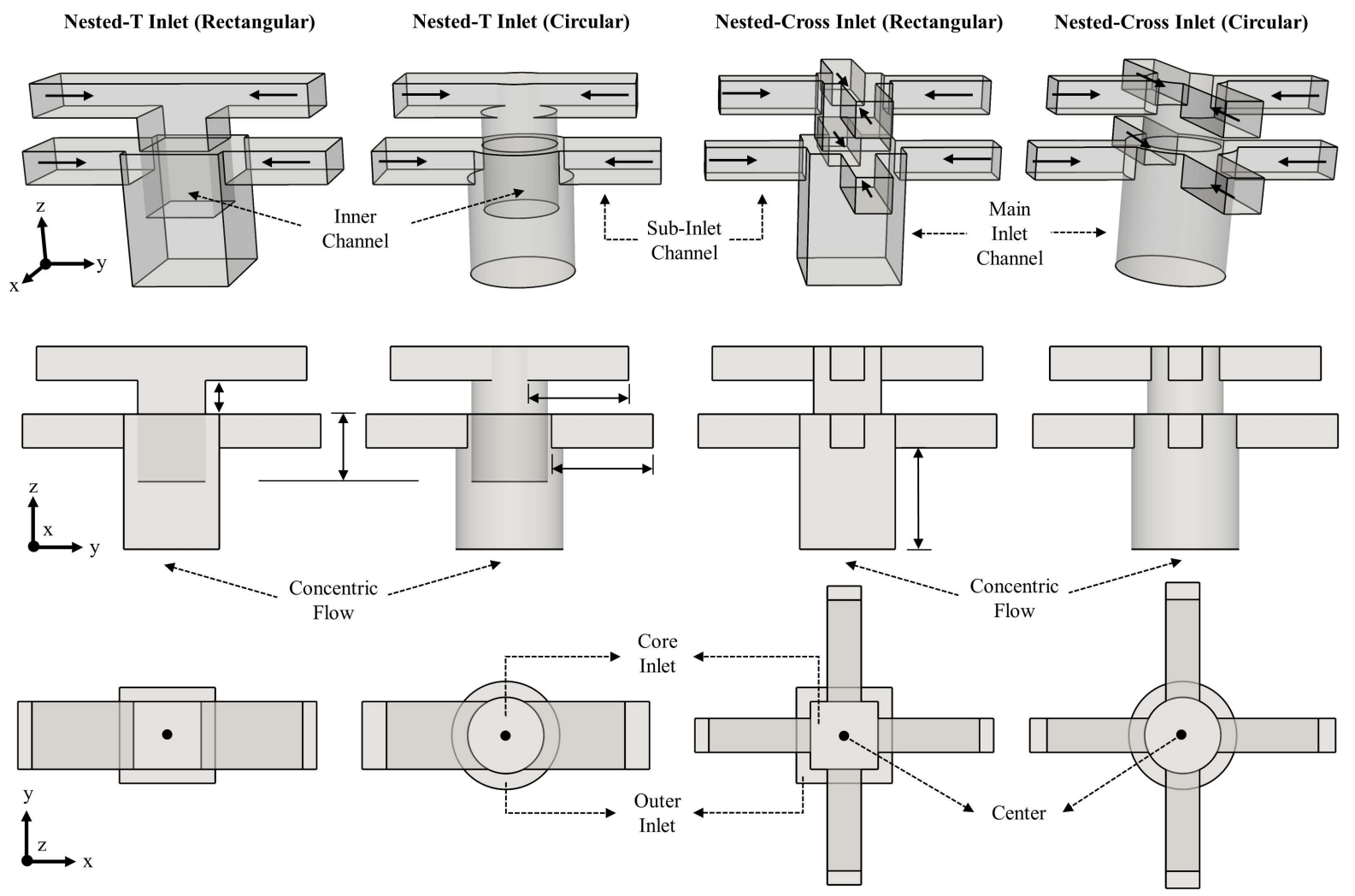

Figure A1. Nested-T (left two columns) and nested-cross (right two columns) inlet structures to create concentric fluid flow in circular and rectangular microchannels. 3-D view (top), yz-plane (middle), and xy-plane (bottom).

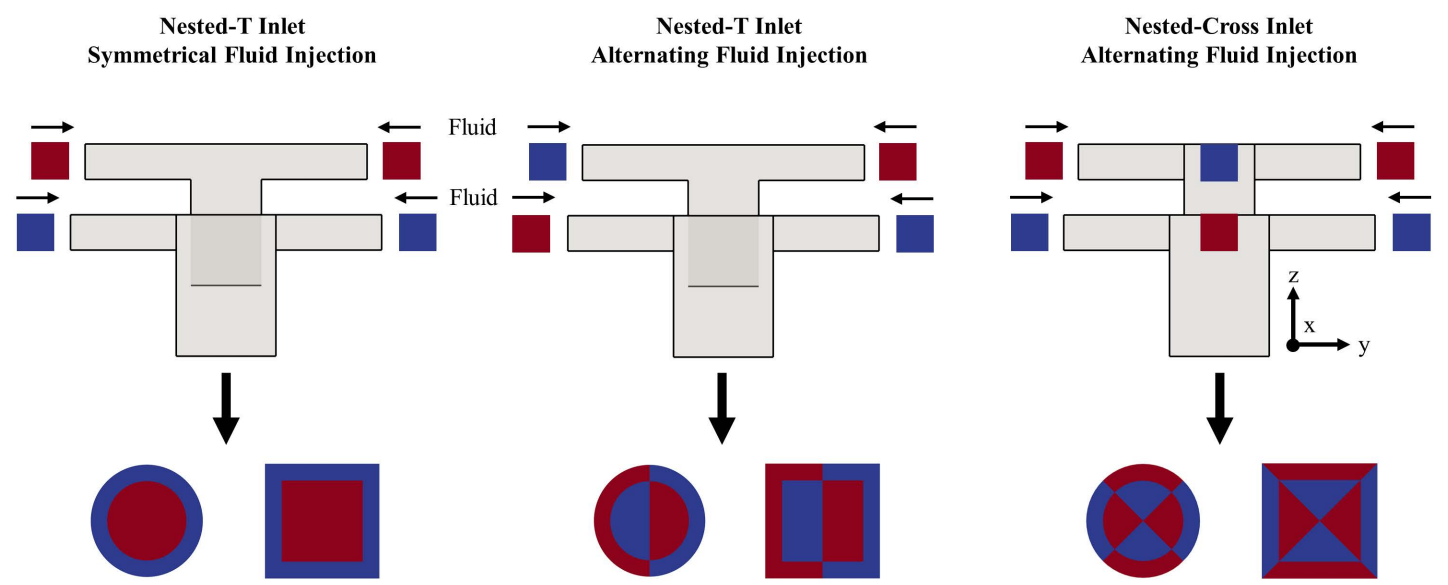

Figure A2. Formation of concentric flows with symmetrical and alternating fluid injections over the nested-t and nestedcross inlet structures. Circular and rectangular planes show the distribution of fluids in concentric flows. Red and blue colors represent different fluids. 

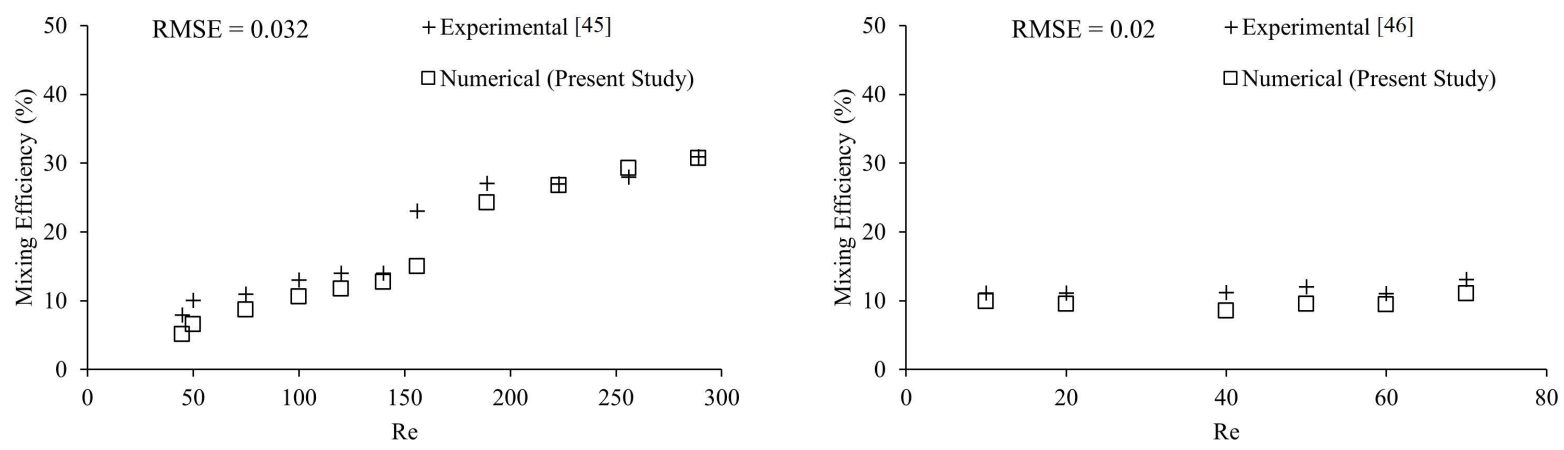

Figure A3. CFD code validation results. Numerical simulation outcomes (present study) against experimental data of two different T-shaped passive micromixers. Root mean square error (RMSE) is used to measure the fit of the numerical simulation results to the experimental data.

(a)

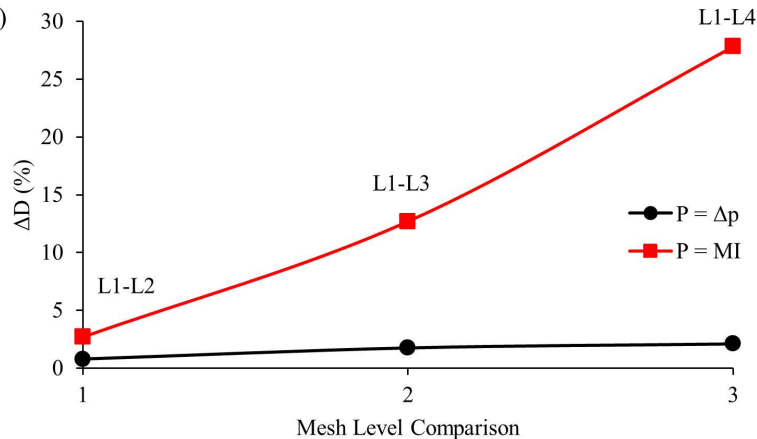

(c)

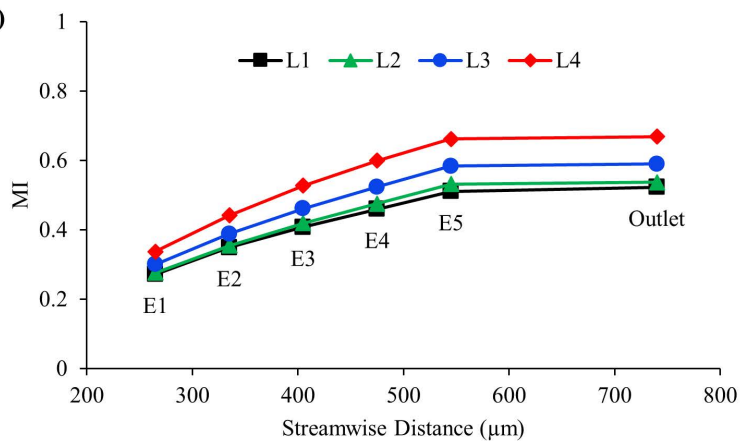

(b)

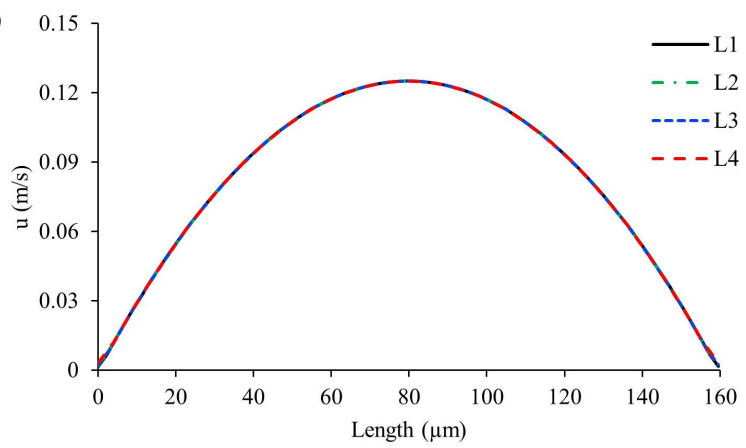

(d)

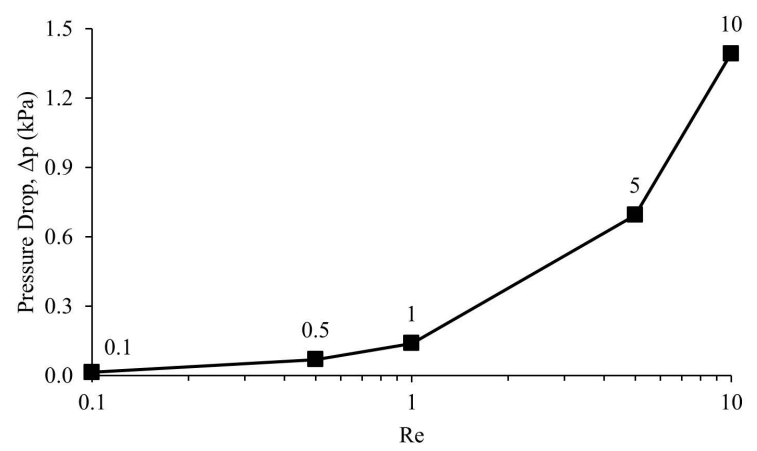

Figure A4. Mesh study outcomes and the change of pressure drop in the CSFO micromixer: (a) difference, as a percentage, between L1 and L2, L3, L4 mesh densities with respect to $\Delta \mathrm{p}$ and MI parameters; (b) velocity distribution on the diameter of outlet cross-section obtained from L1, L2, L3, and L4 mesh level solutions; (c) development of mixing efficiency along the CSFO micromixer in L1, L2, L3, and L4 mesh solutions. MI values are computed on E1, E2, E3, E4, and E5 cross-sections which are normal to the z-direction; (d) $\Delta \mathrm{p}$ vs. Re number in the CSFO micromixer. 


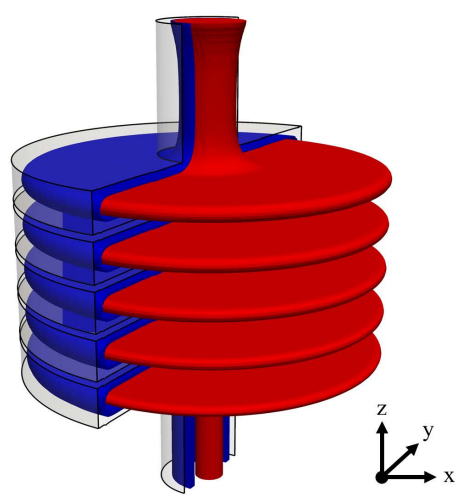

$\downarrow$

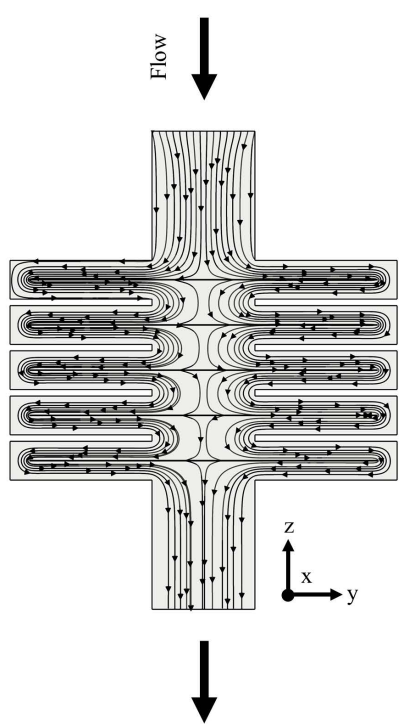

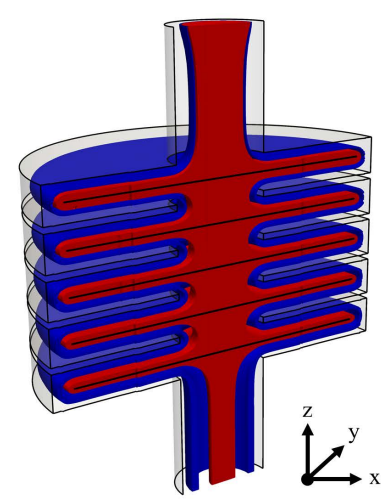

Figure A5. 3-D flow domain and flow pathlines in the CSFO micromixer. Fluid overlapping flow profile (left and right) and flow pathlines between inlet and outlet on the central plane of the CSFO design (center). Red and blue colors show the fluids injected from core and outer inlets, respectively.

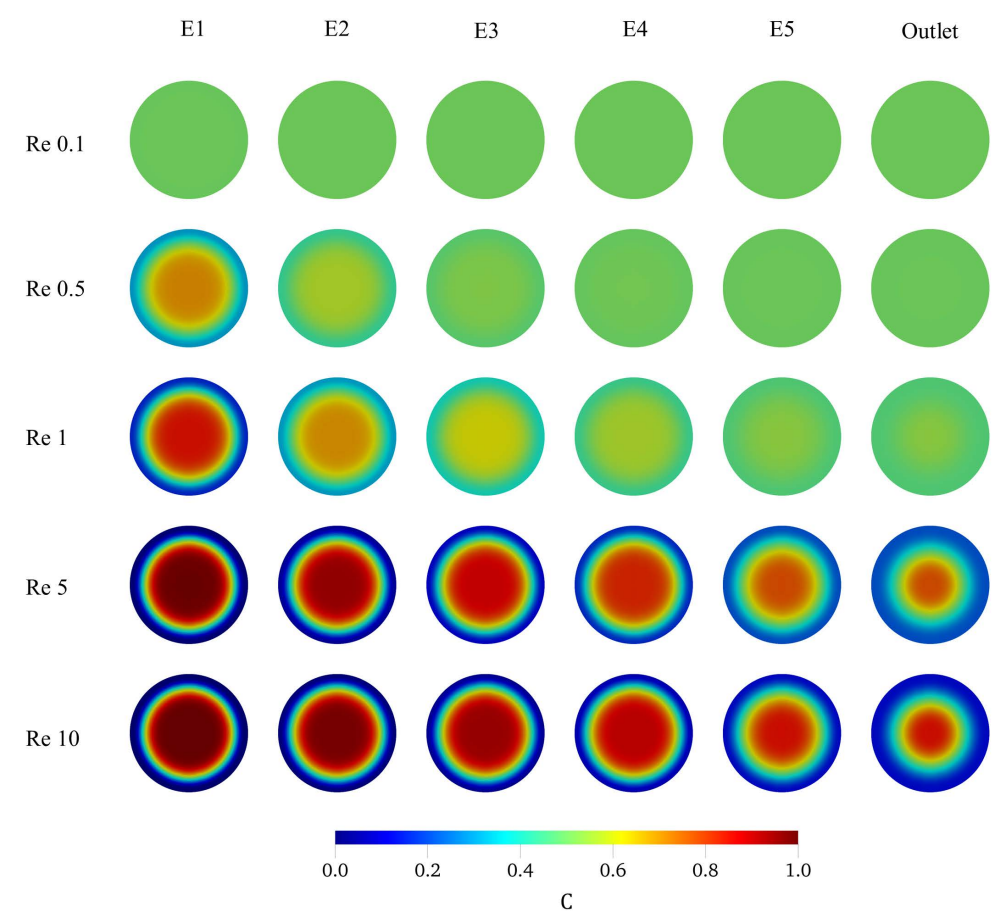

Figure A6. The development of fluid mixing along the CSFO-A micromixer configuration for all flow scenarios of $\mathrm{D}_{1}$ diffusion constant. Circular planes show the distribution of scalar concentration on the exit cross-section of mixing units (E1, E2, E3, E4, and E5) and outlet of the CSFO micromixer. E1, E2, E3, E4, E5, and outlet planes are normal to the z-direction. 

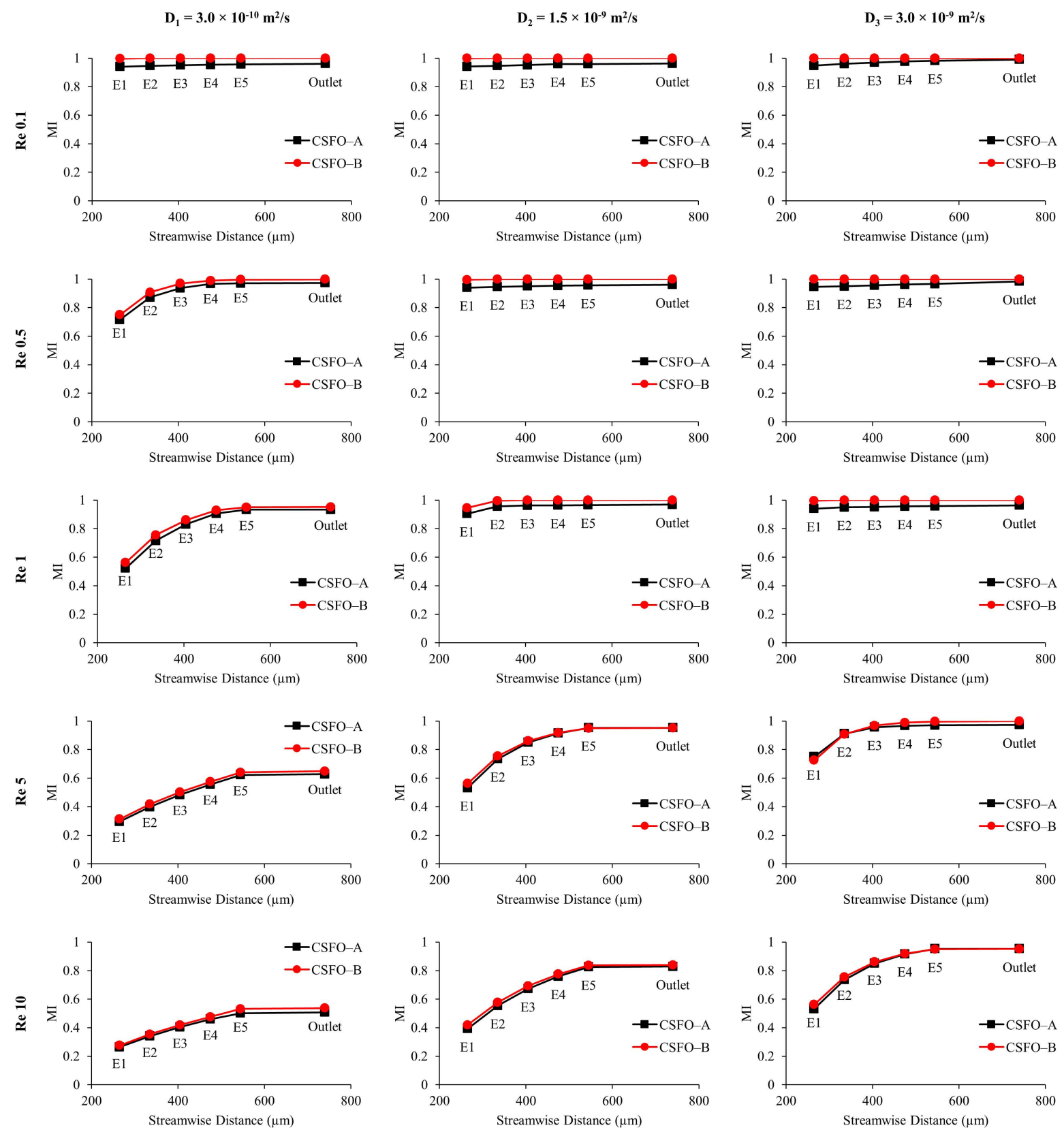

Figure A7. The development of MI along the CSFO-A and CSFO-B micromixer configurations for all flow conditions (i.e., $\mathrm{Re}=0.1,0.5,1,5$, and 10$)$ and molecular diffusion constants $\left(\mathrm{D}_{1}, \mathrm{D}_{2}\right.$, and $\left.\mathrm{D}_{3}\right)$. MI values are calculated on the E1, E2, E3, E4, and $\mathrm{E} 5$ cross-sections which are normal to the $\mathrm{z}$-direction. 
$\operatorname{Re} 1$

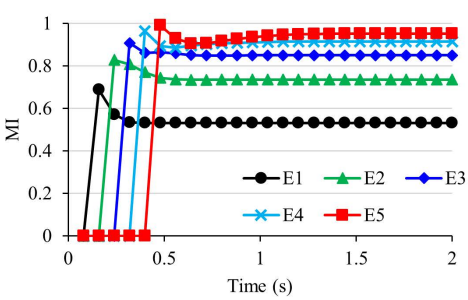

$\mathbf{f}=\mathbf{0 ~ H z}$

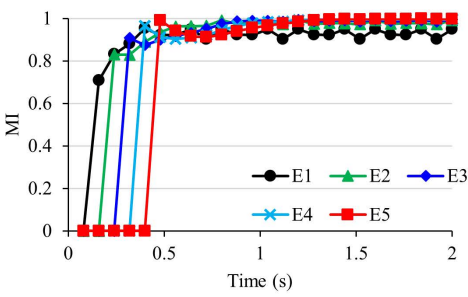

$\mathbf{f}=\mathbf{1 0 ~ H z}$

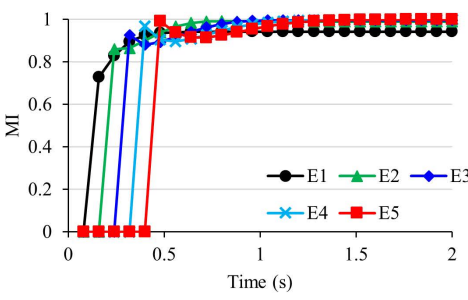

$f=25 \mathrm{~Hz}$

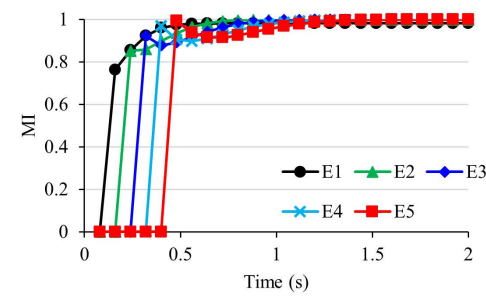

$\mathbf{f}=\mathbf{5 0 ~ H z}$
$\operatorname{Re} 5$

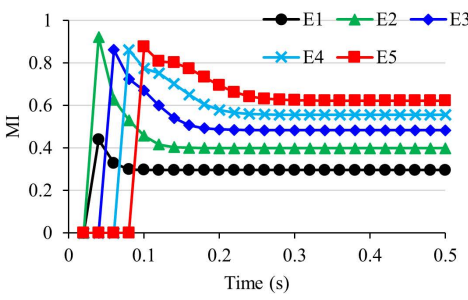

$\mathbf{f}=\mathbf{0 ~ H z}$

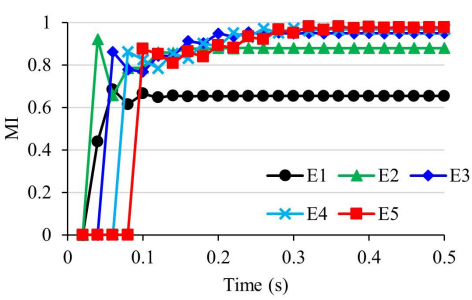

$\mathbf{f}=\mathbf{2 5 ~ H z}$

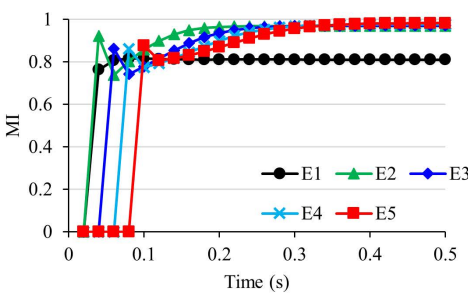

$\mathbf{f}=\mathbf{5 0 ~ H z}$

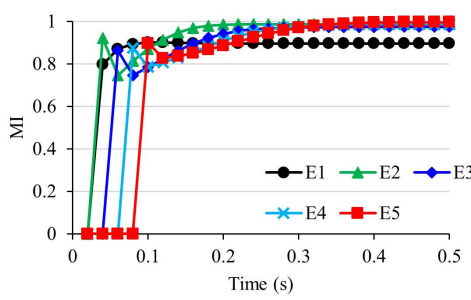

$\mathrm{f}=100 \mathrm{~Hz}$
$\operatorname{Re} 10$

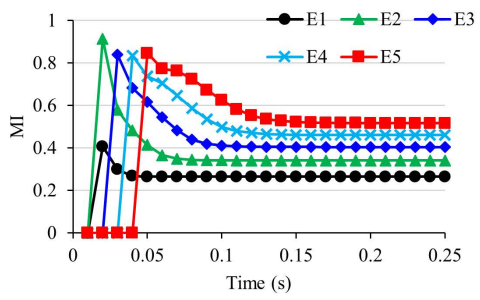

$\mathbf{f}=\mathbf{0 ~ H z}$

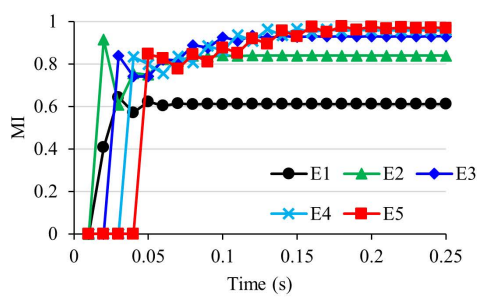

$\mathbf{f}=\mathbf{5 0} \mathbf{H z}$

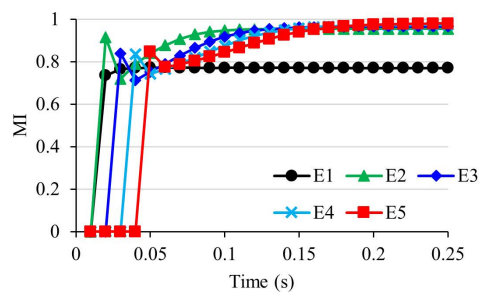

$f=100 ~ H z$

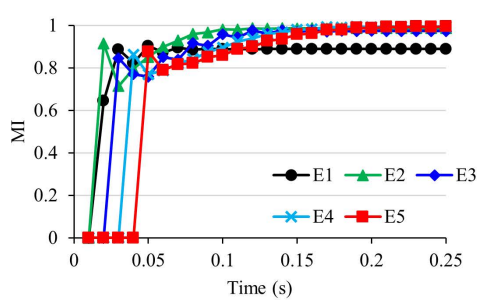

$\mathbf{f}=250 \mathrm{~Hz}$

Figure A8. The development of fluid mixing with respect to time at the exit of mixing units in the CSFO-C micromixer configuration when $\mathrm{Re}=1,5$, and 10 and $\mathrm{D}=\mathrm{D}_{1} . \mathrm{f}=0 \mathrm{~Hz}$ plots (first row) show time-dependent solutions of CSFO-A micromixer. MI values are calculated on the E1, E2, E3, E4, and E5 cross-sections which are normal to the z-direction.

\section{References}

1. Mansur, E.A.; Ye, M.; Wang, Y.; Dai, Y. A state-of-the-art review of mixing in microfluidic mixers. Chin. J. Chem. Eng. 2008, 16, 503-516. [CrossRef]

2. Streets, A.M.; Huang, Y. Chip in a lab: Microfluidics for next generation life science research. Biomicrofluidics $2013,7,011302$. [CrossRef] [PubMed]

3. Park, J.M.; Seo, K.D.; Kwon, T.H. A chaotic micromixer using obstruction-pairs. J. Micromechanics Microengineering 2009, 20, 015023. [CrossRef]

4. Reyes, D.R.; Iossifidis, D.; Auroux, P.-A.; Manz, A. Micro total analysis systems. 1. Introduction, theory, and technology. Anal Chem. 2002, 74, 2623-2636. [CrossRef]

5. Gambhire, S.; Patel, N.; Gambhire, G.; Kale, S. A review on different micromixers and its micromixing within microchannel. Int. J. Curr. Eng. Technol. 2016, 4, 409-413.

6. Nguyen, N.-T.; Wu, Z. Micromixers-A review. J. Micromechanics Microengineering 2005, 15, R1-R16. [CrossRef]

7. Suh, Y.K.; Kang, S. A review on mixing in microfluidics. Micromachines 2010, 1, 82-111. [CrossRef] 
8. Gidde, R.R.; Pawar, P.M.; Ronge, B.P.; Misal, N.D.; Kapurkar, R.B.; Parkhe, A.K. Evaluation of the mixing performance in a planar passive micromixer with circular and square mixing chambers. Microsyst. Technol. 2017, 24, 2599-2610. [CrossRef]

9. Lee, C.Y.; Chang, C.L.; Wang, Y.N.; Fu, L.M. Microfluidic mixing: A review. Int. J. Mol. Sci. 2011, 12, 3263-3287. [CrossRef]

10. Kumar, V.; Paraschivoiu, M.; Nigam, K.D.P. Single-phase fluid flow and mixing in microchannels. Chem. Eng. Sci. 2011, 66, 1329-1373. [CrossRef]

11. Cai, G.; Xue, L.; Zhang, H.; Lin, J. A review on micromixers. Micromachines 2017, 8, 274. [CrossRef]

12. Nguyen, N.-T. Chapter 1-introduction. In Micromixers, 2nd ed.; Nguyen, N.-T., Ed.; William Andrew Publishing: Oxford, UK, 2012; pp. 1-8.

13. Chung, Y.-C.; Hsu, Y.-L.; Jen, C.-P.; Lu, M.-C.; Lin, Y.-C. Design of passive mixers utilizing microfluidic self-circulation in the mixing chamber. Lab A Chip 2004, 4, 70-77. [CrossRef]

14. Alam, A.; Afzal, A.; Kim, K.-Y. Mixing performance of a planar micromixer with circular obstructions in a curved microchannel. Chem. Eng. Res. Des. 2014, 92, 423-434. [CrossRef]

15. Capretto, L.; Cheng, W.; Hill, M.; Zhang, X. Micromixing within microfluidic devices. Top Curr. Chem. 2011, 304, $27-68$.

16. Le The, H.; Le Thanh, H.; Dong, T.; Ta, B.Q.; Tran-Minh, N.; Karlsen, F. An effective passive micromixer with shifted trapezoidal blades using wide reynolds number range. Chem. Eng. Res. Des. 2015, 93, 1-11. [CrossRef]

17. Bhopte, S.; Sammakia, B.; Murray, B. Numerical study of a novel passive micromixer design. In Proceedings of the 2010 12 th IEEE Intersociety Conference on Thermal and Thermomechanical Phenomena in Electronic Systems, Las Vegas, NV, USA, 2-5 June 2010; pp. 1-10.

18. Okuducu, M.B.; Aral, M.M. Novel 3-d t-shaped passive micromixer design with helicoidal flows. Processes 2019, 7, 637. [CrossRef]

19. Chen, X.; Li, T. A novel passive micromixer designed by applying an optimization algorithm to the zigzag microchannel. Chem. Eng. J. 2017, 313, 1406-1414. [CrossRef]

20. Hossain, S.; Ansari, M.A.; Kim, K.-Y. Evaluation of the mixing performance of three passive micromixers. Chem. Eng. J. 2009, 150, 492-501. [CrossRef]

21. Lin, C.-H.; Tsai, C.-H.; Fu, L.-M. A rapid three-dimensional vortex micromixer utilizing self-rotation effects under low reynolds number conditions. J. Micromechanics Microengineering 2005, 15, 935-943. [CrossRef]

22. Tran-Minh, N.; Dong, T.; Karlsen, F. An efficient passive planar micromixer with ellipse-like micropillars for continuous mixing of human blood. Comput. Methods Programs Biomed. 2014, 117, 20-29. [CrossRef]

23. Al-Halhouli, A.a.; Alshare, A.; Mohsen, M.; Matar, M.; Dietzel, A.; Büttgenbach, S. Passive micromixers with interlocking semi-circle and omega-shaped modules: Experiments and simulations. Micromachines 2015, 6, 953-968. [CrossRef]

24. Bhagat, A.A.S.; Peterson, E.T.K.; Papautsky, I. A passive planar micromixer with obstructions for mixing at low reynolds numbers. J. Micromechanics Microengineering 2007, 17, 1017-1024. [CrossRef]

25. Fang, Y.; Ye, Y.; Shen, R.; Zhu, P.; Guo, R.; Hu, Y.; Wu, L. Mixing enhancement by simple periodic geometric features in microchannels. Chem. Eng. J. 2012, 187, 306-310. [CrossRef]

26. Ortega-Casanova, J.; Lai, C.H. Cfd study about the effect of using multiple inlets on the efficiency of a micromixer. Assessment of the optimal inlet configuration working as a microreactor. Chem. Eng. Process. Process Intensif. 2018, 125, 163-172. [CrossRef]

27. Goullet, A.; Glasgow, I.; Aubry, N. Dynamics of microfluidic mixing using time pulsing. Discret. Contin. Dyn. Syst. 2005, 2005, 327-336.

28. OpenFOAM. The Openfoam Foundation, Opencfd Ltd., v5; OpenFOAM: Bracknell, UK, 2015.

29. Warming, R.F.; Beam, R.M. Upwind second-order difference schemes and applications in aerodynamic flows. AIAA J. 1976, 14, 1241-1249. [CrossRef]

30. Wang, L.; Yang, J.-T.; Lyu, P.-C. An overlapping crisscross micromixer. Chem. Eng. Sci. 2007, 62, 711-720. [CrossRef]

31. Moukalled, F.; Mangani, L.; Darwish, M. The Finite Volume Method in Computational Fluid Dynamics: An Advanced Introduction with Openfoam and Matlab; Springer Publishing Company Switzerland, Incorporated: Geneva, Switzerland, $2015 ;$ p. 791.

32. Ansari, M.A.; Kim, K.Y.; Kim, S.M. Numerical and experimental study on mixing performances of simple and vortex micro t-mixers. Micromachines (Basel) 2018, 9, 204. [CrossRef]

33. Roudgar, M.; Brunazzi, E.; Galletti, C.; Mauri, R. Numerical study of split t-micromixers. Chem. Eng. Technol. 2012, 35, 1291-1299. [CrossRef]

34. Okuducu, M.B.; Aral, M.M. Performance analysis and numerical evaluation of mixing in 3-d t-shape passive micromixers. Micromachines 2018, 9, 210. [CrossRef]

35. Zhang, M.; Wu, J.; Wang, L.; Xiao, K.; Wen, W. A simple method for fabricating multi-layer pdms structures for 3d microfluidic chips. Lab A Chip 2010, 10, 1199-1203. [CrossRef]

36. Chen, X. Fabrication and performance evaluation of two multi-layer passive micromixers. Sens. Rev. 2018, 38, 321-325. [CrossRef]

37. Branebjerg, J.; Gravesen, P.; Krog, J.P.; Nielsen, C.R. Fast mixing by lamination. In Proceedings of the Ninth International Workshop on Micro Electromechanical Systems, San Diego, CA, USA, 11-15 February 1996; pp. 441-446.

38. Gray, B.L.; Jaeggi, D.; Mourlas, N.J.; van Drieënhuizen, B.P.; Williams, K.R.; Maluf, N.I.; Kovacs, G.T.A. Novel interconnection technologies for integrated microfluidic systems1paper presented as part of the ssaw-98 workshop.1. Sens. Actuators A Phys. 1999, 77, 57-65. [CrossRef]

39. Yang, J.; Qi, L.; Chen, Y.; Ma, H. Design and fabrication of a three dimensional spiral micromixer. Chin. J. Chem. 2013, 31, 209-214. [CrossRef] 
40. Galletti, C.; Roudgar, M.; Brunazzi, E.; Mauri, R. Effect of inlet conditions on the engulfment pattern in a t-shaped micro-mixer. Chem. Eng. J. 2012, 185-186, 300-313. [CrossRef]

41. Wu, Z.; Nguyen, N.-T.; Huang, X. Nonlinear diffusive mixing in microchannels: Theory and experiments. J. Micromech. Microeng. 2004, 14, 604-611. [CrossRef]

42. Holz, M.; Heil, S.; Sacco, A. Temperature-dependent self-diffusion coefficients of water and six selected molecular liquids for calibration in accurate $1 \mathrm{~h}$ nmr pfg measurements. Phys. Chem. Chem. Phys. 2000, 2, 4740-4742. [CrossRef]

43. Ansari, M.A.; Kim, K.-Y.; Anwar, K.; Kim, S.M. A novel passive micromixer based on unbalanced splits and collisions of fluid streams. J. Micromechanics Microengineering 2010, 20, 055007. [CrossRef]

44. Izadpanah, E.; Hekmat, M.H.; Azimi, H.; Hoseini, H.; Babaie Rabiee, M. Numerical simulation of mixing process in t-shaped and dt-shaped micromixers. Chem. Eng. Commun. 2018, 205, 363-371. [CrossRef]

45. Silva, J.P.; dos Santos, A.; Semiao, V. Experimental characterization of pulsed newtonian fluid flows inside t-shaped micromixers with variable inlets widths. Exp. Therm. Fluid Sci. 2017, 89, 249-258. [CrossRef]

46. Ansari, M.A.; Kim, K.-Y.; Anwar, K.; Kim, S.M. Vortex micro t-mixer with non-aligned inputs. Chem. Eng. J. 2012, 181-182, 846-850. [CrossRef]

47. Okuducu, M.B.; Aral, M.M. Computational evaluation of mixing performance in 3-d swirl-generating passive micromixers. Processes 2019, 7, 121. [CrossRef]

48. Liu, M. Computational study of convective-diffusive mixing in a microchannel mixer. Chem. Eng. Sci. 2011, 66, 2211-2223. [CrossRef]

49. Bailey, R.T. Managing false diffusion during second-order upwind simulations of liquid micromixing. Int. J. Numer. Methods Fluids 2017, 83, 940-959. [CrossRef]

50. Tofteberg, T.; Skolimowski, M.; Andreassen, E.; Geschke, O. A novel passive micromixer: Lamination in a planar channel system. Microfluid. Nanofluidics 2009, 8, 209-215. [CrossRef]

51. Hardt, S.; Schönfeld, F. Laminar mixing in different interdigital micromixers: Ii. Numerical simulations. AIChE J. 2003, 49, 578-584. [CrossRef]

52. Sabry, M.N.; El-Emam, S.H.; Mansour, M.H.; Shouman, M.A. Development of an efficient uniflow comb micromixer for biodiesel production at low reynolds number. Chem. Eng. Process. Process Intensif. 2018, 128, 162-172. [CrossRef]

53. Fujii, T.; Sando, Y.; Higashino, K.; Fujii, Y. A plug and play microfluidic device. Lab Chip 2003, 3, 193-197. [CrossRef]

54. Nguyen, N.-T.; Huang, X. Mixing in microchannels based on hydrodynamic focusing and time-interleaved segmentation: Modelling and experiment. Lab on a chip 2005, 5, 1320-1326. [CrossRef]

55. Nguyen, N.-T.; Huang, X. An analytical model for mixing based on time-interleaved sequential segmentation. Microfluid. Nanofluidics 2005, 1, 373-375. [CrossRef]

56. Glasgow, I.; Lieber, S.; Aubry, N. Parameters influencing pulsed flow mixing in microchannels. Anal. Chem. 2004, 76, 4825-4832. [CrossRef]

57. Alam, A.; Kim, K.-Y. Mixing performance of a planar micromixer with circular chambers and crossing constriction channels. Sens. Actuators B Chem. 2013, 176, 639-652. [CrossRef]

58. Chung, C.K.; Shih, T.R. A rhombic micromixer with asymmetrical flow for enhancing mixing. J. Micromechanics Microengineering 2007, 17, 2495-2504. [CrossRef]

59. Hossain, S.; Lee, I.; Kim, S.M.; Kim, K.-Y. A micromixer with two-layer serpentine crossing channels having excellent mixing performance at low reynolds numbers. Chem. Eng. J. 2017, 327, 268-277. [CrossRef]

60. Sadegh Cheri, M.; Latifi, H.; Salehi Moghaddam, M.; Shahraki, H. Simulation and experimental investigation of planar micromixers with short-mixing-length. Chem. Eng. J. 2013, 234, 247-255. [CrossRef]

61. Ansari, M.A.; Kim, K.-Y. Mixing performance of unbalanced split and recombine micomixers with circular and rhombic subchannels. Chem. Eng. J. 2010, 162, 760-767. [CrossRef]

62. Raza, W.; Hossain, S.; Kim, K.-Y. Effective mixing in a short serpentine split-and-recombination micromixer. Sens. Actuators $B$ Chem. 2018, 258, 381-392. [CrossRef] 